\title{
Casein Kinase I Isoform Alpha
}

National Cancer Institute

\section{Source}

National Cancer Institute. Casein Kinase I Isoform Alpha. NCI Thesaurus. Code C26033.

Casein kinase I isoform alpha (337 aa, $\sim 39 \mathrm{kDa}$ ) is encoded by the human CSNK1A1 gene.

This protein plays a role in both protein phosphorylation and receptor-mediated signaling. 